\title{
DEPRAVED, DISTRACTED, DISABLED, OR JUST "PACK RATS"? WORKPLACE HOARDING PERSONAS IN PHYSICAL AND VIRTUAL REALMS
}

\author{
Jo ANN ORAVEC
}

\section{ABSTRACT}

This article provides some potential directions in exploring the construction of the persona of the "hoarder" and addresses how such a persona can move to the foreground of an individual's set of workplace-related personas. Hoarding throws into relief some critical concerns about the social standings of individuals in workplaces and the extent to which they have autonomous expression. The article frames hoarding in terms of its capacity to externalize particular social issues (such as environmental problems) and generate public discourse, and examines both physical hoardings (books and papers in academic and office settings, for example) and hoardings of virtual goods (such as digital music, video files, and pornographic images). Virtual hoardings have been constructed as problematic as they create barriers to the free flow of information in the workplace and can challenge organizational interests related to intellectual property concerns. Hoarding as a whole is becoming more tightly circumscribed as a workplace and community condition, in part because the ability to manage physical and virtual items in confined settings is considered central to many forms of competent societal functioning.

An assortment of human resource management initiatives to mitigate hoarding concerns has developed, including the consideration of hoarding as a disability. However, hoarding behavior is increasing creating problems for those who are searching for simple definitions or straightforward diagnostic criteria. This article also provides some structures for analysis of the class-related and economic dimensions of workplace hoarding personas, and explores potential implications of lifelogging initiatives and hoarding acceptance approaches.

\section{KEY WORDS}

Hoarding, Persona, Workplace disability, Anxiety, Popular culture, Virtual goods, Class, Lifelogging

\section{INTRODUCTION}

A number of individuals openly claim to be "pack rats" and exhibit some level of disorganization in workplaces (Diekema and Olsen 2261), and they often express sympathy for those similarly afflicted. However, those who are considered hoarders can receive highly negative treatment in workplace organizations, often damaging their well-being and careers (Mataix-Cols 2023; Ronan 249). This article analyzes how individuals in the workplace can acquire a hoarder persona among their other personas, and explores how this persona can take 
on a predominant status. As related in the article, treatments of hoarding in popular culture along with recent psychological research have served to shape workplace discourse on hoarding as well as expand the implications of hoarding personas, especially in relation to disability and other workplace considerations. As critics have noted, individuals are associated with more than one persona (see Broady); however, the "hoarder" persona frequently moves to the foreground of the personas with which individuals couple themselves and are coupled in workplace contexts. The hoarding persona has, in recent years, been so overwhelming in its influence as to shift identities like "creative employee" or "kind friend" into the background. In the past decade, the notion of hoarding has expanded its place in public discourse in the US and UK with an assortment of news accounts, self-help books, and television "reality shows" (Lepselter 919; Weinman 77). Oft-times this workplace hoarder identity is framed in terms of general notions of disability. If hoarding is, indeed, framed as a disability in organizations, the impact of being characterized as a hoarder could be considerable and may require the introduction of mental health and organizational accommodation.

\section{HOARDING CONTEXTS AND HISTORIES}

Hoarding can elicit deep emotional connections in many of us, especially those who have considerable experience working with large collections of artifacts, papers, and books. It can be difficult to part with items one has a personal connection, such as items owned by a deceased relative or colleague. Many individuals with academic connections know stories about a staff or faculty member who has been personally affected by hoarding. For example, the widelydiscussed case of the late Margaret Mary Vojtko of Duquesne University in the US, a French language instructor (discussed in Ellis), made many academics reconsider their own situations. Vojtko was an adjunct member of the faculty who accumulated many materials related to the accomplishments of her students (as well as her own intellectual products) in storage garages and various spaces granted to her by friends and colleagues. The Collyer Brothers, collectors of more than 140 tons of material (including many books and newspapers) in a Manhattan apartment building in the 1940s, have attracted the interest of psychological researchers for decades (Weiss 251). The Collyer Brothers' story did not end well: they were both found dead among their possessions. Hoarding is also becoming an international concern and studies in the European Union (EU) and US demonstrate that it is a growing phenomenon (Mueller et al. 709). An article in the Australian and New Zealand Journal of Psychiatry by Paul Fitzgerald characterizes cases of severe hoarding as "the bowerbird symptom," reflecting the tendencies of the animal mentioned to hoard (597). Other social scientists and commentators have referred to a "hoarding instinct" (Conniff 92) and hoarding behavior has been studied in animals and humans that are facing certain resource stresses (Bergstrom 10860), However, research on hoarding has been relatively slow to emerge despite the "significant distress and impairment" often associated with the condition (Coles et al., 180). Virtual hoarding issues have been even slower to gain attention from researchers.

The overall relationship of modern society to physical goods has been problematic, so it is not surprising that hoarding is often portrayed as harmful to personal well-being at home and at work. Books such as Should the U.S. Reduce Its Consumption? (2011) and The Story of Stuff: The Impact of Overconsumption on the Planet, Our Communities, and Our Health-And How We Can Make It Better (2010) remind us that overconsumption is a critical problem, even threatening, and related to global climate and energy change. Individuals are informed from many sources that one of the solutions to society's economic and ecological problems involves smaller buildings with less "stuff" in them. Despite these anti-consumption initiatives, individuals also face an onslaught of marketing messages and advertising materials tempting them to buy even more items; they are also advised by public safety and survivalist groups about the prospects of impending shortages or dramatically increased prices for goods and 
services. In Hoarders, Doomsday Preppers, and the Culture of Apocalypse (2014), Foster explores how individuals deal with projected disasters and crises through hoarding certain kinds of personal possessions. Hoarding is often the result of chronic shortages during extended periods of disaster and war (Solnit P2), so new forms of hoarding associated with the recent economic austerity crises in the US and Europe may emerge. The result of these conflicting messages is often cognitive dissonance and confusion (Thomas and Mora 1).

The notion that possessions can somehow own or control their owners in dysfunctional ways has been a persistent theme in Western cultures for some time now. As American author Henry David Thoreau noted in 1845: "Most of the luxuries, and many of the so-called comforts of life, are not only not indispensable, but positive hindrances to the elevation of [hu]mankind" (8). In 1917, British philosopher Bertrand Russell also argued that, "It is preoccupation with possession, more than anything else, that prevents men [and women] from living freely and nobly" (154). Today, "voluntary simplifiers" extol the political as well as personal benefits of reducing one's physical belongings (Zamwel, Sasson-Levy, and Ben-Porat 199), and frame personal accumulations in terms of larger environmental problems. Platitudes about the positive aspects of living with fewer and/or well-organized belongings are, indeed, lofty and inspiring, but they often fail to recognize the societal demands for competent interactions with material goods. For example, in order competently to interact with government bureaucracy, maintain one's medications and medical apparatus, and arrange for adequate nutrition, one must acquire and organize substantial quantities of material items. However, navigating the narrow straits of proper societal functioning in terms of these items can be difficult: how many things should a normally-functioning employee or household member accumulate? How should these entities be organized and maintained? American author Mark Twain (Samuel Clemens) reportedly hoarded the letters of his many correspondents, an activity that may have appeared eccentric at the time, but which has given his biographers an incredible wealth of information (Rasmussen xiii).

\section{CONTESTED TERRAINS: HOARDING AND THE WORKPLACE}

Efforts to characterize "hoarding" can lead to complex and contentious discussions. In 2013, after lengthy debate, "Hoarding Disorder" was included in the DSM-5 (Diagnostic and Statistical Manual of Mental Disorders, published by the American Psychiatric Association). The label is reportedly intended to cover cases in which hoarding occurs independently from, or in the absence of, other kinds of mental conditions. The DSM-5 defines Hoarding Disorder as "persistent difficulty discarding or parting with possessions, regardless of their actual value" (American Psychiatric Association 236), a behavior that can also be linked with various forms of anxiety. An often-cited characterization of hoarding is an "excessive form of collectionism" (Pertusa et al. 372), in which possessions take on extended levels of value and significance. Distinctions between collectionism (intense focuses on the part of individuals on organizing and completing assemblages of certain kinds of items) and hoarding (which is generally perceived as disorganized) are complex and status- or class-related differences often play a role in how collecting behavior is constructed.

Those who have the means to live with considerable, well-organized possessions are generally not considered "hoarders" but "collectors." Nicely-stocked offices, closets, or pantries are considered the result of diligence; the piles of materials associated with hoarding are construed in less appreciative terms. The fact that physical possessions often have monetary dimensions can introduce class-related aspects: individuals who are less well positioned in relation to their organizational or neighborhood standards can be construed as a hoarder for retaining a relatively-small number of possessions in the restrictive spaces in which they work 
or live. In contrast, those who can afford large houses and storage garages, or in workplace contexts, larger offices and efficient secretarial help, can amass much more before such an identity moves to the foreground. In fact, almost a third of those surveyed in a number of Western nations state that they are, indeed, "collectors" of some particular items (Pearce 1). Belk et al. distinguish between "hoardings" and "collections" in characterizations of how possessions relate to the construction of self. Collections may be of the same size as hoardings, but have more specific structures and meanings: "We take collecting to be the selective, active, and longitudinal acquisition, possession and disposition of an interrelated set of differentiated objects (material things, ideas, beings or experiences)" (181). Those who collect items are often driven to add to their accumulations, but at the same time might worry that their newest acquisitions will somehow "complete" their collections and thus an aspect of their motivation for continuing to collect may be diminished. The performativity of hoarding behavior, in contrast, seldom has such specific patterns and motivations, either in terms of the kinds of items involved or in how they are organized, stored, and acquired. In an effort to determine possible patterns, some researchers have recently attempted to map the connections between hoarding and compulsive buying (Lawrence et al. 1137; Mueller et al. 709).

Workplaces are scenes for many kinds of struggles for resources and social standing between and among individuals, conflicts that can intensify as economic conditions place strains on organizations. Attention to hoarding in many workplaces has expanded as office space and other resources become more expensive and the everyday surveillance and oversight of employees escalates. The workplace has increasingly become "contested terrain" (Edwards and Edwards vii), with employees and management often perceiving their interests to differ. Part of this contested terrain notion involves the basic characterization of employees: are they to be considered autonomous individuals or as entities under the strict control of supervisors? Office and shop floor décor can play a role in fostering individuality and giving individuals more leeway in their expressions (Elsbach 99). When employees alter their workspaces through hoarding they may enter into larger contests and struggles concerning how individuals are construed and how the scope of activity of supervisors is determined.

A hoarding persona in workplace contexts is performed and expressed by individuals through various kinds of behavior in relation to physical or virtual items. Some of these performances may involve the accumulation and stockpiling of particular entities. Other hoarding performances may enact the neglect of certain functions: hoarders may be confused about, be unable to replicate, or simply refuse to perform the regular cleaning, arrangement, and disposal behaviors that are the accepted norms for their workplaces. As described in sections to come, these performances are generally enacted within the limited stage and scope of the workplace setting and are circumscribed by the workplace's economic and cultural setting. Individuals may adopt the persona of hoarder despite the relatively small size of the hoardings involved, perhaps because the items in question may appear to lack organization. The amount of material involved in workplace hoarding can be a tiny fraction of the resources associated with the organization, but can still be considered a "hoard" by co-workers or clients (Herring Hoarders 8). Employees who are construed or construe themselves as hoarders are often linked with the appropriation of resources and physical or virtual space, and manifest some kind of deviance from accepted, delimited organizational patterns. Many workplaces are also becoming sites of hoardings of virtual goods, which affects the free flow of organizational information and raises questions about the competence and diligence of the individuals involved (Gormley and Gormley 90). On the other hand, employees who are compliant in terms of physical and virtual resources may be seen as more adaptable: in workplace cultures, employees who are able to shift their relationships with their possessions and other objects 
appropriately and quickly in order to meet the assumed needs of institutions are preferable to those, such as hoarders, who cannot or will not.

\section{HoARDing AND Human REsource MANAGEMENT AND DisABILITy STUdies}

Hoarding narratives are becoming a focus of the business community in the US and UK. For instance, an article in Forbes magazine, a widely-read American financial publication, described hoarding as a "real" and "tragic" condition, directly countering some of the more sensationalistic coverage in television and print portrayals (Haiken 1). The persona of the hoarder in these contexts is often linked to waste and loss although the economic and social encumbrances that hoarding places on workplaces and communities are difficult to weigh (for example, the opportunity costs associated with the decreases in functional working space and the loss of usable items that are hidden from view) (Tolin et al. "The Economic" 200). Although some workplaces have strict policies about personal belongings or tightly control the amount of organizational resources that employees can access, others provide enough leeway and discretion so as to enable hoarding to become a factor (Kim 496; Murphy 22).

The approach of some organizations to hoarding behaviour has been to frame it as a disability, following the American Psychiatric Association's classification of "Hoarding Disorder" (Herring Hoarders 3). However, introducing disability-related themes may also increase the complexities of the hoarding persona and, in some situations, its stigma. In a positive light, such a framework could stimulate the allocation of expenditures for counseling or the redesigning of spaces and tasks. Unfortunately, this would require employer resources in a job market where resources are often stretched thin and problematic employees more readily dismissed. Like many human conditions associated with disability in the workplace, individuals are often labeled as hoarders without professional diagnosis and are managed by concerned others (such as supervisory personel), who lack the proper professional qualificiations to manage this issue (Murphy 23): the piles of materials associated with the individual are considered sufficient evidence. Considering hoarding as a disability could also involve social interventions in workplace contexts: psychologists are generating a number of narratives pertaining to social anxieties and the social isolation of hoarders. Some portray these conditions as self-imposed and others as linked to external triggers (Steketee and Frost 21; Vigne et al. 315).

More detailed and systematic strategies for characterizing and diagnosing hoarding are emerging. Development of these strategies is made more complex by the vast differences in the situations and demographics (and, possibly, the neural structures) of individuals associated with the persona of "hoarder" (Wang et al. 939). For example, hoarding is an activity that affects multiple demographics. It is reportedly making an appearance among college-aged students (Coles, Frost, Heimberg, and Steketee 179), who are often present in workplaces for internships and other early employment opportunities. At the same time, as the number of relatively older individuals in workplace and community settings rises, compulsive hoarding cases also seem to be increasing (Ayers et al. 741). In the past decade, efforts to develop diagnostic scales for hoarding in workplaces and mental health settings have included the 26-item Saving InventoryRevised (Coles et al. 179) and the briefer, interview-format Hoarding Rating Scale-Interview (HRS-I) (Tolin, Frost, and Steketee 147). Another research initiative involves mapping the linkages of some forms of hoarding to Obsessive Compulsive Disorder (OCD) (Neal-Barnett and Mendelson 169). In some workplace settings, hoarding has already been linked with problems akin to those of OCD (Santuzzi et al. 204), which raises critical questions concerning disclosure of the conditions involved, potential treatment, and accommodation. Some therapists are using images of hoardings to diagnose hoarding cases (de la Cruz et al. 61). In one kind of treatment strategy, images of hoardings are also being employed to mitigate its effects; Jones and Singh 
have used images of hoarders' possessions in non-threatening therapy contexts to help desensitize hoarders to related anxieties (41). Adding to the complexities of diagnosis and treatment, some theorists have posited that hoarding may in itself serve as a defense mechanism, serving to shield the individual from even more debilitating behaviour (Hudson 57).

The interpersonal dimensions of hoarding also complicate its construction as a disability (Grisham, Steketee, and Frost E63): the stereotype of hoarders as isolated loners has been modified in recent years because many individuals are highly social but also have hoarding tendencies. Many of those who are portrayed or who self-identify as hoarders are highly functional in various aspects of their personal and professional realms, possibly even overcompensating in some areas such as in personal dress and self-maintenance (Steketee and Frost 21). Assisting these highly-functional individuals to find ways to establish control over their physical and virtual possessions as they have over other aspects of their lives (O'Connor 101; Woody 324) may empower them to maintain the kinds of routines and everyday activities that can mitigate the consequences of hoarding behavior. However, many individuals characterized as hoarders do have considerable difficulties in terms of social interaction (Rasmussen et al. 384). In response, some community approaches to hoarding have involved task forces of concerned citizens dedicated to dealing in a sensitive manner with the multifaceted issues of often isolated and frightened individuals (Bratiotis).

\section{HOARDERS, HEAL THYSELVES: SELF-HELP FOR HOARDERS?}

Self-help literatures and other simple, low-cost remedies for human maladies have emerged for hoarding, as they have for many other conditions that have been constructed as being problematic (such as weight loss and self-esteem issues). Human resource managers (as well as the general public) might be tempted by the notion that reading a book or watching a video can help to change or recharacterize behavior. However, societal stigmas are often reflected in these self-help materials and can muddy attempts to understand hoarding and deal with its consequences. For example, some popular non-fiction accounts of compulsive buying (Shulman) can place some kinds of hoarding in the light of avarice and pleasure rather than as a struggle with serious medical conditions such as OCD (as portrayed in Frost et al. "Compulsive Buying" 201). Many individuals who are characterized as "overweight" have comparable issues involving how their situation is construed. Some books have even linked hoarding with weight issues, such as Breininger's Stuff Your Face Or Face Your Stuff: The Organized Approach to Lose Weight by Decluttering Your Life (2013). Discrimination against those who weigh more than a certain amount in relation to their heights is rampant in many workplace contexts whatever the roots of their conditions (Magallares, Morales, and Rubio 255) and their physiques are often openly mocked rather than treated with respect. Those who are labele $d$ as "hoarders" face comparably negative conditions, although the amount of discrimination in workplaces against hoarders has yet to be determined (Bratiotis, Schmalisch, and Steketee 10).

A large number of books have emerged that outline specific "how to" steps and selftherapy strategies for individuals associated with hoarding. Books such as Overcoming Compulsive Hoarding: Why You Save and How You Can Stop (Bubrick et al.) attempt to deliver strategies for individuals to overcome their perceived problems. Other approaches incorporate greater levels of critical self-examination and reproach: Cluttered Lives, Empty Souls: Compulsive Stealing, Spending, and Hoarding (Shulman) links the hoarding of possessions with various character faults and even crimes. "Tell all" books such as Dirty Secret: A Daughter Comes Clean About Her Mother's Hoarding (Sholl) and Diary of a Hoarder's Daughter (Winter) are designed to assist individuals through the supposed true-life confessionals of others. Many of the US 
nationally-syndicated talk shows (including the US television show Dr. Phil) have covered hoarding issues multiple times (Lepselter 919). Given the widespread dissemination of these books and television shows, hoarding narratives rooted in workplace and community contexts apparently have substantial voyeuristic value, particularly in an era of unsettling economic changes.

Individuals who are linked to hoarding behaviours often produce coherent narratives and arguments about their situation and can articulate why specific items are retained. The hoarders themselves have some control over these narratives, but other accounts (such as reports of health inspectors or other officials) are largely out of their direct spheres of influence. In The Hoarding Handbook: A Guide for Human Service Professionals, Bratiotis, Schmalisch, and Steketee state that people are "simultaneously appalled and drawn to the stories of hoarding" (11), making these narratives attractive yet controversial matter for popular treatment in media. Moreover, these media narratives are often produced and disseminated by those who have little personal connection with the hoarders involved. Television series have provided many amateur workplace diagnosticians with basic knowledge of hoarding. For example, The Learning Channel (TLC) in the US premiered a documentary series Hoarding: Buried Alive on March 14, 2010 that served to make its viewers more aware of the condition. The series provided detailed case studies of individuals who accepted the label of "hoarders" and agreed (at least at first) to work with both an organizational expert and a psychologist on their conditions. In these reality TV shows and documentaries, economic conditions are often connected to hoarding activities. For instance, some individuals rationalize hoarding by explaining that they had few possessions as children and now do not know how to handle abundance; others construe the hoarding of everyday items as related to the fear of current or future economic losses. In Patterson, Hogan, and Willis (5), the authors provide an account of how hoarding tendences are related to childhood deficiencies in material items caused by poverty.

\section{ISSUES OF VIRTUAL HOARDING AND WORKPLACE REDESIGN}

The"virtual hoarder" is a relatively new aspect of hoarding behaviour and its relation to physical hoarding is uncertain.

i Virtual hoarding has some correlation to physical hoarding in terms of organization and stewardship practices: many individuals are effectively misplacing or damaging digital files through not providing sufficient tags and by not updating files from out-of-date formats (Gormley and Gormley 22). This behavior can result in losses to organizations that are comparable to those of physical resource losses as information needed for organizational operations is taken out of circulation ("Is It Workplace Hoarding?" 3). Virtual items that are hoarded have evolved from simple e-mail address rosters to collections of highly detailed avatars and complex online game strategies (Ng and Höpfl 751; Oravec Virtual 47). Kirk and Sellen, as well as Good, have categorized an assortment of the personal media archives that are often collected and maintained by individuals and households, assemblages that include digital images associated with vacations and other family events. In terms of its immediate physical footprint, however, the collection of digital books that can be stored on even a modest computer system is tiny in relation to a comparable assortment of physical, pulp-based books. While physical workplace and community hoardings can provide substantial safety and public health issues, the accumulation of virtual goods has fairly little physical impact. Moreover, the hoarding of virtual items has not yet been shown to be a direct substitute (or object of transference) for the hoarding of physical items; some hoarders of physical goods are not hoarders of virtual goods, and vice versa (Fried). 
Identifying individuals who violate workplace sharing norms in physical or virtual realms as "hoarders" can serve to identify and possibly isolate them. As the hoarding persona moves to the foreground, other personas of these individuals that could make them appear as valuable to the organization can be diminished. Gormley and Gormley discuss how data hoarding is manifested in employee behavior, stating that "hoarding data can create a false sense of uncertainty avoidance" (90). As individuals accumulate organizational information, but do not process and share it, they remove certain information resources out of the hands of colleagues in strategic ways (Evans, Hendron, and Oldroyd 494). The possibility that certain individuals would take it upon themselves to collect and store workplace-owned digital resources that are not made available to other organizational members could be seen as parallel to the concerns of many employers about the hoarding of physical goods. The model of the employee as existing as part of a system controlled by others in the organization, and not as an autonomous entity, reflects persistent workplace conflicts between the individual and the collective.

Hoarders of virtual goods may be unable to decipher the accepted organizational standards concerning the organization and storage of digital entities, or have increased anxieties linked to the standards' complexities or contradictions. Some organizations do not have clear distinctions between what is retained because of organizational needs and what is indeed "hoarded" ("Is It Workplace Hoarding?" 3). Managerial determinations here are often based on perceived institutional needs but can have considerable personal impacts as they affect how managers and co-workers deal with the behavior of individuals. For example, virtual files retained over time need to be managed by employees: changes in file formats through the years can make archived documents either useless or very costly to decipher. The orderliness of the physical and virtual assets of organizations often increases their perceived value by managers (Kim 496), so hoarding behavior related to the organization's virtual and physical goods can have economic dimensions and thus attract more of the attention of managers. Legal issues can arise as documents relating to product defects or other unfortunate workplace matters are buried in the files of employees or as copyright infringement issues emerge. In the workplace, the hoarding of pornographic images in organization-owned computers and online networks has also become a problem, one that is especially curious because of the fact that the individuals involved could readily download and store the materials on their own digital devices rather than endanger their careers by using organizational resources (Oravec "Ethics" 137). When employees use the computer equipment provided in their workplace for such activity (rather than their own smartphone or computer tablet), it may reveal a great deal about the individuals' judgment. Aggressive managerial efforts to detect and diagnose hoarding behavior in the virtual realm either for economic or legal purposes could increase the surveillance of employees and magnify workplace privacy issues, which are already substantial concerns in many organizational contexts (Sprague 83).

\section{SOME CONCLUSIONS AND REFLECTIONS}

Research on the persona of the hoarder in workplace contexts is just beginning and researchers are unclear as to its dimensions, especially in virtual realms. For individuals whose hoarding behavior has some linkages to concerns about memory losses, the digital recording of everyday events may eventually provide some relief and perhaps serve to reframe hoarding behaviors. Some individuals are already engaged in experiments in which their entire lives are being taped ("lifelogging") so that any slippage in memory could be compensated (Lupton 77; Wolf et al. 8). As proposed by Baraniuk and others, missing items could be replaced through 3D printing on demand (46). Perhaps these dramatic ways of supplementing and even enhancing 
individuals' memories and memorabilia may eventually serve to alter some of the dysfunctional patterns that lead to hoarding. However, lifelogging practices could also engender new forms of dysfunction as individuals are called upon to be responsible for more (real or virtual) artifacts, narratives, and memories. Workplace demands for detailed decision-making on the disposition of countless physical as well as virtual items could increase with the enhanced capabilities for detailed recall that lifelogging provides.

Providing basic support and empowerment for all individuals in organizations is part of establishing a just society (Campbell and Oliver 125). Designing workplace environments in which the management of organizational resources and personal possessions can be performed in a more humane, less stressful, and less time-consuming manner can aid organizations as well as individuals. Rather than framing individuals as "hoarders" (which has overwhelming negative implications), employers can enable employees to deal with problems in terms of organization and retention of physical and virtual items. Sets of clearly-stated policies concerning how much and what kinds of personalization of the workplace is acceptable may be helpful (Brandes and Erlhoff 16), relieving the stress of interpreting complex and changing workplace standards. These environmental and social accommodations would probably also lift the decision-making burdens of many individuals in the workplace, not just those who are labeled as "hoarders." After such changes, the persona of the hoarder might still be one of many that are associated with an individual, but its implications could be less severe and its placement less in the foreground.

For individuals who are currently or will soon be participating in organizational decision making, becoming aware of hoarding behavior issues can help to catalyze positive change. Discussing hoarding in workplace contexts may help employees and management become sensitive to the situations of the individuals involved and, perhaps, displace the hoarder persona from its prominent (and frequently dominant) position. The opportunistic use of images of hoardings by organizations to individuate and control individuals (despite the pain these efforts may cause the individuals involved), also raises issues about autonomy, respect, privacy, and human rights. In dealing with hoarding issues, it is important to remember that human beings with feelings and needs are involved. The shame associated with hoarding can be painful and may certainly be reinforced by the use of insensitive approaches. As "Mad Pride," disability acceptance, and comparable initiatives clear a path for the expression of the voices of those who are associated with varied psychological conditions, there indeed may be hope for those whose lives are somehow linked with hoarding (see Campbell and Oliver 62). Instead of placing the onus primarily on individuals to deal with hoarding behavior, organizations and communities can work to provide accommodations, possibly by moderating their considerable demands on individuals in terms of the management and storage of possessions. Understanding and acceptance on the part of all involved, along with the generation and analyses of creative approaches, may go a substantial distance toward mitigating these concerns.

\section{END NOTES}

i It bears pointing out that the computer equipment that is utilized by hoarders for the collection of these virtual items raises another workplace issue: the often horrifying working conditions of those who manufacture these technologies (Mayer 19). 


\section{WORKS CITED}

American Psychiatric Association. Diagnostic and Statistical Manual of Mental Disorders. 5th ed. Washington, D.C.: American Psychiatric Association, 2013. Print.

Ayers, Catherine R., Princeton Ly, Ian Howard, Tina Mayes, Ben Porter, and Yasmeen Iqbal. "Hoarding Severity Predicts Functional Disability in Latelife Hoarding Disorder Patients." International Journal of Geriatric Psychiatry 29.7 (2014): 741-746. Print.

Baraniuk, Chris. "Things to Come." New Scientist 221.2962 (2014): 46-47. Print.

Belk, Russell W., Melanie Wallendorf, John F. Sherry, and Morris B. Holbrook. "Collecting in a Consumer Culture." Highways and Buyways: Naturalistic Research from the Consumer Behavior Odyssey. (1991): 178-215. Print.

Bergstrom, Theodore C. "On the Evolution of Hoarding, Risk-taking, and Wealth Distribution in Nonhuman and Human Populations." Proceedings of the National Academy of Sciences 111.Supplement 3 (2014): 10860-10867. Print.

Brandes, Uta, and Michael Erlhoff, eds. My Desk is My Castle: Exploring Personalization Cultures. Boston: Walter de Gruyter, 2012. Print.

Bratiotis, Christiana. Task Force Community Response to Compulsive Hoarding Cases. Ph.D. Dissertation, Boston University, 3363599 (2009). Print.

Bratiotis, Christiana, Cristina Sorrentino Schmalisch, and Gail Steketee. The Hoarding Handbook: A Guide for Human Service Professionals. New York: Oxford UP, 2011. Print.

Breininger, Dorothy. Stuff Your Face Or Face Your Stuff: The Organized Approach to Lose Weight by Decluttering Your Life. Deerfield Beach, Florida: Health Communications, Inc. (HCI). 2013. Print.

Broady, Timothy R. “The Carer Persona: Masking Individual Identities.” Persona Studies 1.1 (2015): 65-75. Print.

Bubrick, Jerome, Fugen Neziroglu, and Jose Yaryura-Tobias. Overcoming Compulsive Hoarding: Why You Save and How You Can Stop. Oakland, CA: New Harbinger Publications, 2004. Print.

Campbell, Jane, and Mike Oliver. Disability Politics: Understanding Our Past, Changing Our Future. New York: Routledge, 2013. Print.

Canale, Anthony, and Bradley Klontz. "Hoarding Disorder: It's More Than Just an ObsessionImplications for Financial Therapists and Planners." Journal of Financial Therapy 4.2 (2013): 43-63. Print.

Coles, Meredith E., Randy O. Frost, Richard G. Heimberg, and Gail Steketee. "Hoarding Behaviors in a Large College Sample.” Behaviour Research and Therapy 41.2 (2003): 179-194. Print.

Conniff, Richard. “The Hoarding Instinct.” Smithsonian 42.9 (2012): 92. Print.

de la Cruz, Lorena Fernández, Ashley E. Nordsletten, Danielle Billotti, and David Mataix-Cols. "Photograph-aided Assessment of Clutter in Hoarding Disorder: Is a Picture Worth a Thousand Words?" Depression and Anxiety 30.1 (2013): 61-66. Print.

Diekema, Anne R., and M. Whitney Olsen. "Teacher Personal Information Management (PIM) Practices: Finding, Keeping, and ReFinding Information." Journal of the Association for Information Science and Technology 65.11 (2014): 2261-2277. Print.

Edwards, Richard C., and Richard Edwards. Contested Terrain: The Transformation of the Workplace in the Twentieth Century. New York: Basic Books, 1979. Print.

Ellis, Lindsay. "An Adjunct's Death Becomes a Rallying Cry for Many in Academe." Chronicle of Higher Education. Chronicle. 19 Sept. 2013. Web. 20 Sept. 2015.

Elsbach, Kimberly D. "Interpreting Workplace Identities: The Role of Office Décor." Journal of Organizational Behavior 25.1 (2004): 99-128. Print.

Evans, Joel M., Michael G. Hendron, and James B. Oldroyd. "Withholding the Ace: The Individualand Unit-Level Performance Effects of Self-Reported and Perceived Knowledge Hoarding." Organization Science 26.2 (2014): 494-510. Print. 
Fitzgerald, Paul B. "The 'Bowerbird Symptom': A Case of Severe Hoarding of Possessions." Australian and New Zealand Journal of Psychiatry 31.4 (1997): 597-600. Print.

Foster, Gwendolyn Audrey. Hoarders, Doomsday Preppers, and the Culture of Apocalypse. New York: Palgrave Macmillan, 2014. Print.

Fried, Daniel. "Compulsive Hoarding: Psychopathologies of Print, Phenomenologies of Text." Culture, Theory, and Critique 55.3 (2014). Print.

Frost, Randy O., Gail Steketee, and Lauren Williams. "Compulsive Buying, Compulsive Hoarding, and Obsessive-Compulsive Disorder." Behavior Therapy 33.2 (2002): 201-214. Print.

Good, Katie Day. "From Scrapbook to Facebook: A History of Personal Media Assemblage and Archives." New Media \& Society 15.4 (2013): 557-573. Print.

Gormley, Cynthia J., and Samantha J. Gormley. "Data Hoarding and Information Clutter: The Impact on Cost, Life Span of Data, Effectiveness, Sharing, Productivity, and Knowledge Management Culture." Issues in Information Systems 13.2 (2012): 90-95. Print.

Grisham, Jessica, Gail Steketee, and Randy 0. Frost. "Interpersonal Problems and Emotional Intelligence in Compulsive Hoarding." Depression and Anxiety 25.9 (2008): E63-E81. Print.

Haiken, Melanie. "The Surprising New Truth About Hoarding Disorder" Forbes. Forbes, 19 Nov. 2013. Web. 20 Sept. 2015.

Haugen, David, and Susan Musser. Should the U.S. Reduce Its Consumption? Farmington Hills: Greenhaven Press, 2011. Print.

Herring, Scott. “Collyer Curiosa: A Brief History of Hoarding." Criticism, 53.2 (2011): 159-188. Print.

---. The Hoarders: Material Deviance in Modern American Culture. U of Chicago P, 2014. Print.

Hudson, Wayne C. "Persona and Defence Mechanisms." Journal of Analytical Psychology 23.1 (1978): 54-62. Print.

"Is It Workplace Hoarding ... Or Record-Keeping?" Administrative Professional Today 40.3 (2014): 3. Print.

Jones, Colin, and Satwant Singh. "The Experience of Emotional Distancing in the Management of Compulsive Hoarding: A Visual Methods Approach Using The 'Hoard' Acronym Tool." Journal of Cognitive-Behavioral Psychotherapy and Research 2.1 (2013): 41-46. Print.

Kibby, Marjorie. "Collect Yourself: Negotiating Personal Music Archives." Information, Communication \& Society 12.3 (2009): 428-443. Print.

Kim, Seok Eun. "Physical Workplace as a Strategic Asset for Improving Performance in Public Organizations." Administration \& Society 46.5 (2014): 496-518. Print.

Kirk, David S., and Abigail Sellen. "On Human Remains: Values and Practice in the Home Archiving of Cherished Objects." ACM Transactions on Computer-Human Interaction (TOCHI) 17.3 (2010): 10. Print.

Lawrence, Lee Matthew, Joseph Ciorciari, and Michael Kyrios. "Relationships that Compulsive Buying Has with Addiction, Obsessive-compulsiveness, Hoarding, and Depression." Comprehensive Psychiatry 55.5 (2014): 1137-1145. Print.

Leonard, Annie. The Story of Stuff: How Our Obsession with Stuff Is Trashing the Planet, Our Communities, and Our Health-and a Vision for Change. New York: Simon \& Schuster, 2010. Print.

Lepselter, Susan. “The Disorder of Things: Hoarding Narratives in Popular Media." Anthropological Quarterly 84.4 (2011): 919-947. Print.

Lupton, Deborah. "Self-tracking Cultures: Towards a Sociology of Personal Informatics." Proceedings of the 26th Australian Computer-Human Interaction Conference on Designing Futures: the Future of Design. Association for Computing Machinery (ACM) (2014): 7786. Print.

Magallares, Alejandro, Jose Morales, and Miguel Rubio. "The Effect of Work Discrimination on the Well-being of Obese People." International Journal of Psychology \& Psychological Therapy 11.2 (2011): 255-267. Print.

Mataix-Cols, David. "Hoarding Disorder.” New England Journal of Medicine 370.21 (2014): 202330. Print. 
Mayer, Vicki. Below the Line: Producers and Production Studies in the New Television Economy. Durham: Duke UP, 2011. Print.

Mueller, Astrid, Ross D. Crosby, Heide Glaesmer, and Martina de Zwaan. "The Prevalence of Compulsive Hoarding and its Association with Compulsive Buying in a German Population-based Sample." Behaviour Research and Therapy 47.8 (2009): 705-709. Print.

Murphy, Kathryn. "The High Cost of Hoarding Disorder." Nursing Management 45.6 (2014): 2026. Print.

Neal-Barnett, Angela, and Lorre Mendelson. "Obsessive Compulsive Disorder in the Workplace: An Invisible Disability." Women \& Therapy 26.1/2 (2003): 169. Print.

$\mathrm{Ng}$, Ricky Yuk-kwan, and Heather Höpfl. "Objects in Exile: The Intimate Structures of Resistance and Consolation." Journal of Organizational Change Management 24.6 (2011): 751-766. Print.

O'Connor, John. "To Hold On or to Let Go? Loss and Substitution in the Process of Hoarding." European Journal of Psychotherapy \& Counselling 16.2 (2014): 101-113. Print.

Oravec, Jo Ann. Virtual Individuals, Virtual Groups: Human Dimensions of Groupware and Computer Networking. New York: Cambridge UP, 1996. Print.

---. "The Ethics of Sexting: Issues Involving Consent and the Production of Intimate Content." Digital Ethics. Eds. Don Heider and Adrienne L. Massanari. New York: Peter Lang, 2012. 129-145. Print.

Paterson, Jennifer, Jessica Hogan, and Heather Willis. “Vision, Passion, Action: Reflections on Learning to Do Disability Studies in the Classroom and Beyond." Disability Studies Quarterly 28.4 (2008): 1-11. Web. 20 Sept. 2015.

Pearce, Susan. Collecting in Contemporary Practice. New York: Sage, 1997.

Pertusa, Alberto, Randy O. Frost, Miguel A. Fullana, Jack Samuels, Gail Steketee, David Tolin, Sanjaya Saxena, James F. Leckman, and David Mataix-Cols. "Refining the Diagnostic Boundaries of Compulsive Hoarding: A Critical Review." Clinical Psychology Review 30.4 (2010): 371-386. Print.

Rasmussen, Jessica, Gail Steketee, Michelle Silverman, and Sabine Wilhelm. "The Relationship of Hoarding Symptoms to Schizotypal Personality and Cognitive Schemas in an OCD Sample." Journal of Cognitive Psychotherapy 27.4(2013): 384-396. Print.

Rasmussen, R. Kent. Dear Mark Twain: Letters from his readers. U of California P, 2014. Print.

Ronan, Keith P. "Navigating the Goat Paths: Compulsive Hoarding, or Collyer Brothers Syndrome, and the Legal Reality of Clutter." Rutgers Law Review 64 (2011): 235-264. Print.

Russell, Bertrand. Principles of Social Reconstruction. New York: Routledge. 1917/1997. Print.

Santuzzi, Alecia M., Pamela R. Waltz, Lisa M. Finkelstein, and Deborah E. Rupp. "Invisible Disabilities: Unique Challenges for Employees and Organizations." Industrial and Organizational Psychology 7.2 (2014): 204-219. Print.

Sholl, Jessie. Dirty Secret: A Daughter Comes Clean about her Mother's Hoarding. Gallery Books, 2010. Print.

Shulman, Terrence. Cluttered Lives, Empty Souls: Compulsive Stealing, Spending, and Hoarding. San Carlos: Infinity, 2011. Print.

Solnit, Rebecca. A Paradise Built in Hell: The Extraordinary Communities that Arise in Disaster. New York: Penguin, 2010. Print.

Sprague, Robert. "Orwell was an Optimist: the Evolution of Privacy in the United States and its De-evolution for American Employees." John Marshall Law Review 42 (2008): 83-134. Print.

Steketee, Gail, and Randy Frost. Stuff: Compulsive Hoarding and the Meaning of Things. New York: Houghton Mifflin Harcourt, 2010. Print.

Thomas, J. A., and K. Mora. "Community Resilience, Latent Resources and Resource Scarcity after an Earthquake: Is Society Really Three Meals Away from Anarchy?" Natural Hazards 74.2 (2014): 1-14. Print.

Thoreau, Henry D. Walden. New York: Dover Thrift Editions, 1845/1995. Print. 
Tolin, David F., Randy O. Frost, and Gail Steketee. "A Brief Interview for Assessing Compulsive Hoarding: The Hoarding Rating Scale-Interview." Psychiatry Research 178.1 (2010): 147152. Print.

Tolin, David F., Randy O. Frost, Gail Steketee, Krista D. Gray, and Kristin E. Fitch. "The Economic and Social Burden of Compulsive Hoarding." Psychiatry Research 160.2 (2008): 200-211. Print.

Vigne, Paula, Gabriela B. de Menezes, Murat Yucel, and Leonardo F. Fontenelle. "Can Hoarding be a Symptom of Social Anxiety Disorder? A Case Study." The International Journal of Psychiatry in Medicine 46.3 (2013): 315-23. Print.

Wang, John M., Rachael D. Seidler, Julie L. Hall, and Stephanie D. Preston. "The Neural Bases Of Acquisitiveness: Decisions To Acquire And Discard Everyday Goods Differ Across Frames, Items, And Individuals." Neuropsychologia 50.5 (2012): 939-948. Print.

Weinman, Jaime J. “Can't Get Enough Of Compulsive Hoarders.” Maclean's 124.1 (2011): 77. Print.

Weiss, Kenneth J. "Hoarding, Hermitage, and the Law: Why We Love the Collyer Brothers." Journal of the American Academy of Psychiatry and the Law 38.2 (2010): 251-257. Print.

Winter, Izabelle. Diary of a Hoarder's Daughter. Amazon Digital Services, 2014. Print.

Wolf, Katrin, Albrecht Schmidt, Agon Bexheti, and Marc Langheinrich. "Lifelogging: You're Wearing a Camera?" IEEE Pervasive Computing 13.3 (2014): 8-12. Print.

Woody, Sheila R., Kirstie Kellman-McFarlane, and Alison Welsted. "Review of Cognitive Performance in Hoarding Disorder." Clinical Psychology Review 34.4 (2014): 324-336. Print.

Zamwel, Einat, Orna Sasson-Levy, and Guy Ben-Porat. "Voluntary Simplifiers as Political Consumers: Individuals Practicing Politics through Reduced Consumption." Journal of Consumer Culture 14.2 (2014): 199-217. Print.

Jo Ann Oravec is a professor of information technology in the College of Business and Economics at the University of Wisconsin at Whitewater. She has chaired the Privacy Council of the State of Wisconsin and has written extensively on privacy, American studies, artificial intelligence, futurism, online reputational systems, and emerging technologies. 